\title{
Corrosion and electrochemical behavior of steel in hardening concrete
}

\author{
I.A. Gedvillo, A.S. Zhmakina, N.N. Andreev and S.S. Vesely \\ A.N. Frumkin Institute of Physical Chemistry and Electrochemistry, Russian Academy \\ of Sciences, Leninsky pr. 31, Moscow, 119071 Russian Federation \\ E-mail:n.andreev@mail.ru
}

\begin{abstract}
It has been shown using corrosion and electrochemical methods that reinforcing steel is subject to pitting during the initial period of concrete hardening. It is intensified if chlorides are present in the tempering water and/or if corrosion products exist on the metal surface. IFKhAN-80 inhibitor added with tempering water hinders pit formation on steel during concrete hardening, up to complete suppression of this process. Even at high chloride concentrations and in the presence of corrosion products on the metal surface, reinforcing steel in concrete is passivated some time after concrete tempering.
\end{abstract}

Key words: corrosion in concrete, corrosion inhibitors in concrete, reinforced concrete.

Received: February 8, 2017. Published: February 20, 2017.

doi: $\underline{10.17675 / 2305-6894-2017-6-1-7}$

\section{Introduction}

The pore liquid in concrete is highly alkaline. Because of that, reinforcing steel in concrete is usually passive. It is generally believed that it is depassivated by chlorides (which enter concrete from the outside or are added with tempering water) upon acidification of the pore liquid due to absorption of carbon dioxide from the air $[1,2]$. Concrete carbonation is a slow process, and depassivation sites (pits) appear on the reinforcement by the above mechanism for a long time after reinforced concrete structures have been put into service. However, the results published previously $[3,4]$ give a reason to believe that reinforcement can undergo pitting even during concrete curing when the pore liquid has not yet become sufficiently alkaline for passivation. The resulting pits may serve as mechanical stress points and concrete delamination sites, thus weakening reinforced concrete structures considerably. However, it has to be admitted that the electrochemical behavior of steel at initial stages of concrete hardening has been studied insufficiently.

This work aimed at studying the corrosion and electrochemical behavior of reinforcing steel in concrete at various hardening times, both in the absence and in the presence of chlorides and/or IFKhAN-80 inhibitor. The latter has been developed at the Institute of Physical Chemistry of the Russian Academy of Sciences and is positioned as a versatile (contact and migrating) corrosion inhibitor for concrete reinforcing steel [3-8]. 


\section{Experimental}

Specialized concrete samples were manufactured for electrochemical measurements. They were made using cubic moldings made of laminated cardboard, with $70 \mathrm{~mm}$ side and a removable bottom. A stainless steel plate serving as the auxiliary electrode in electrochemical measurements was arranged along one side of each molding. The plate protruded outside the molding to provide electric contact with the potentiostat. The moldings were filled with concrete paste prepared by mixing cement, sand and water. We used 2 parts of sand screened through a $2 \mathrm{~mm}$ sieve and 0.4 parts of water per 1 part of Portland cement PTs 500 D0. Concrete was tempered with tap water. In some tests, sodium chloride (3\% of the cement mass) and/or IFKhAN-80 corrosion inhibitor (same amount) were added to the tempering water.

St3ps steel rods $6.5 \mathrm{~mm}$ in diameter and $50 \mathrm{~mm}$ in length were used as the working electrodes. They were pre-cleaned with emery paper, degreased with ethanol, and kept for $24 \mathrm{~h}$ in a desiccator with calcined calcium chloride. Part of the length of each rod was coated with bituminous varnish. After varnish drying, some of the electrodes were placed for 30 days in a cabinet with $100 \%$ humidity to create a thin rust layer on the metal surface.

The working electrodes were immersed into the moldings filled with concrete paste so that the cement-air interface corresponded to the coated surface or the metal rods. The varnish was removed from the upper parts of the rods in order to connect them to a potentiostat. Prior to polarization of a rod, the bottom was removed from the molding and the latter was immersed in a Petri dish containing tap water. A silver chloride reference electrode was also immersed in the dish. The potentials reported in the paper were measured versus this electrode and were not converted to the hydrogen scale.

Anodic potentiostatic curves were recorded on a P-5848 potentiostat at various periods of time after concrete tempering, from the steady potential to $1000 \mathrm{mV}$ (or till the current density exceeded $50 \mu \mathrm{A} / \mathrm{cm}^{2}$ ). The potential was changed by $100 \mathrm{mV}$ once every minute.

To perform visual inspection of the corrosion state of steel, pieces of reinforcing steel were cleaned, degreased and dried as described above, then totally immersed into concrete with the same composition as that used in the electrochemical studies. After $24 \mathrm{~h}$ of concrete hardening, it was chipped off and the metal surface was examined.

\section{Experimental results and discussion}

\section{Steel with pre-cleaned surface}

In the absence of additives, steel undergoes intense pitting during the first hours of concrete hardening. This is demonstrated by an abrupt current increase even upon a small anodic shift of the potential (Figure 1) during the first hour of the experiment. During the first day, most likely during the first hours of steel exposure in the hardening concrete environment, pits covered with corrosion products well visible after concrete removal were 
formed on its surface. Two hours later, a region where current depends on potential only slightly appears on the polarization curves. Though the current density in this region was rather high and exceeded $10 \mu \mathrm{A} / \mathrm{cm}^{2}$ in some areas, the width of the passive range was about $1.2 \mathrm{~V}$. Further, current increased abruptly at potentials near $0.7 \mathrm{~V}$. Subsequent steel exposure in hardening concrete resulted in a current density decrease in the passive region and in some broadening of the latter.
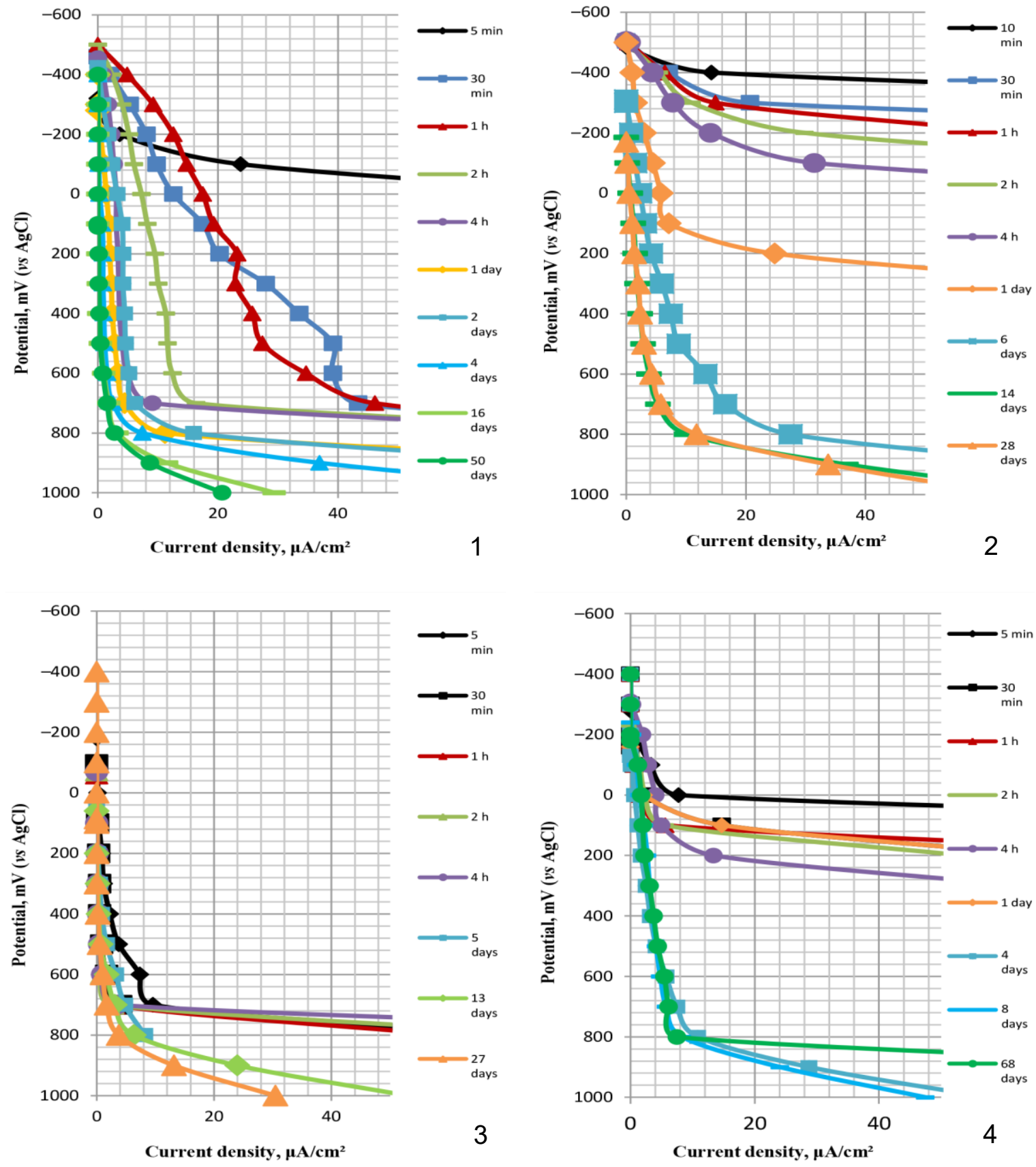

Figure 1. Anodic polarization curves of pre-cleaned steel in concrete after various hardening times: 1 , concrete without additives; 2, concrete with addition of $\mathrm{NaCl}$; 3, concrete with addition of IFKhAN-80; 4, concrete with addition of $\mathrm{NaCl}$ and IFKhAN-80. 
Addition of sodium chloride to concrete did not change the situation essentially. However, steel passivation occurred at markedly longer times of concrete hardening. Judging by the polarization curves, steel transition to the passive state occurred $c a$. 2 weeks after the start of the experiments. Multiple pits were noticeable on the metal exposed for $24 \mathrm{~h}$ in hardening concrete.

IFKhAN-80 inhibitor totally prevented pit corrosion of steel during concrete hardening. Steel was passive starting from the first minutes of the experiment. No corrosion pits were observed on the metal exposed for $24 \mathrm{~h}$ in hardening concrete.

Simultaneous addition of sodium chloride and IFKhAN-80 gave a picture similar to that observed in concrete hardening without additives. Steel that underwent pitting at initial stages of concrete hardening was soon passivated and remained passive throughout the experiment. Very small local corrosion sites were found on steel electrodes exposed for $24 \mathrm{~h}$ in hardening concrete. Apparently, IFKhAN-80 hinders local corrosion but does not prevent it completely. It may be believed that, in general, the effect of IFKhAN-80 depends on the ratio of inhibitor and chloride concentrations in concrete.

A clearer idea about the corrosion and electrochemical behavior of steel in hardening concrete and about the effects of the additives in question can be gained by comparing the time dependences of criterial characteristics of the anodic behavior of steel identified on the polarization curves, rather than the curves themselves. As such characteristics, we used the potential at $10 \mu \mathrm{A} / \mathrm{cm}^{2}$ current density, which in the first approximation characterizes the passive film breakdown potential, and the current density at $0.4 \mathrm{~V}$, which reflects the currents in the passive state.

The time dependences of these criteria for concretes with various compositions are presented in Figure 2. The most positive breakdown potentials, including those at early stages of hardening, are observed in concrete with addition of IFKhAN-80, whereas the most negative potentials are found in concrete containing sodium chloride. The dependences obtained in concrete without additives and in concrete containing both additives occupy an intermediate position. The differences in potentials level off with time.

The same regularities are characteristic of the time dependences of the current densities in the passive region. Concrete with the inhibitor demonstrates the lowest current densities, whereas that with sodium chloride, the highest current densities. The current densities in the passive region for concretes without additives and with both additives lie in-between. Like the breakdown potentials, the differences level off with time.

Thus, steel is liable to pitting corrosion in the initial period of concrete hardening, even in the absence of chlorides. Chlorides added with tempering water strongly intensify this corrosion and increase the time required for passivation of reinforcing steel. IFKhAN80 added to concrete with tempering water allows pitting to be suppressed completely in the absence of chlorides, or this process to be hindered if chlorides are present. Irrespective of the presence or absence of chlorides, reinforcing steel in concrete undergoes passivation some time after concrete tempering. 

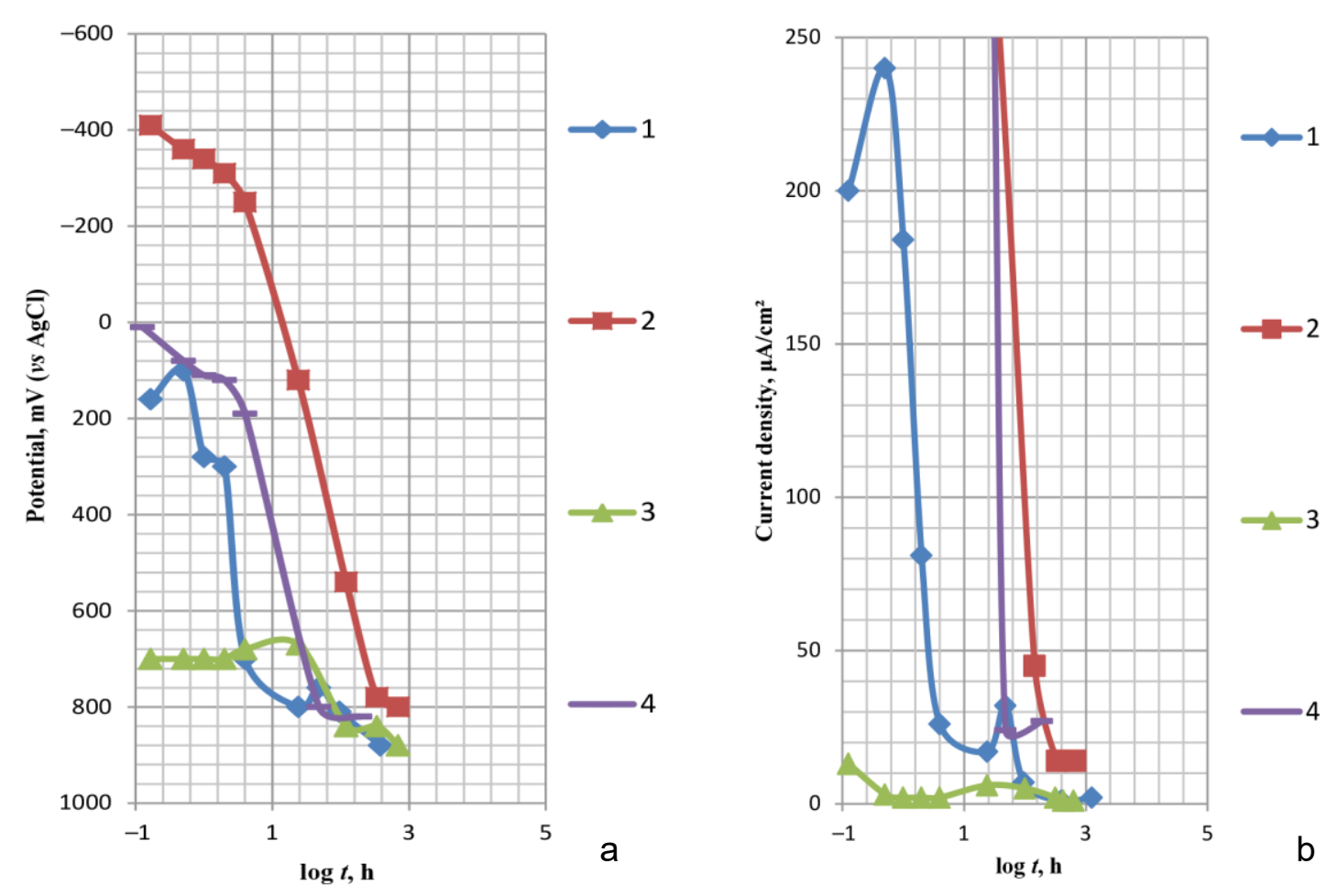

Figure 2. Dependences of breakdown potential $(a)$ and current density in the passive region (b) for pre-cleaned steel versus time of concrete hardening: 1, concrete without additives;

2 , concrete with addition of $\mathrm{NaCl} ; 3$, concrete with addition of IFKhAN-80; 4, concrete with addition of $\mathrm{NaCl}$ and IFKhAN-80.

\section{Steel covered with corrosion products}

The regularities reported above are characteristic of steel without corrosion products on the surface. In real life, rusty reinforcing steel is commonly used in the building of reinforced concrete structures. In such cases, it is recommended to treat it with neutral rust converters, e.g., IFKhAN-58PR. However, these recommendations are often neglected. This has an adverse effect on the strength characteristics of concrete. The second part of this study deals with the effect of rust on the anodic behavior of reinforcing steel in concrete during its hardening.

The anodic polarization curves of steel covered with corrosion products in hardening concrete without additives or in the presence of chlorides and/or IFKhAN-80 are shown in Figure 3.

In comparison with pre-cleaned steel, rust-covered steel is characterized by more negative breakdown potentials and higher current densities in the passive state (Figure 4). The differences are especially noticeable at short times of concrete hardening. These data allow us to assume that local corrosion is intensified. However, rusty steel is passivated with time, and the difference between its polarization curves and the curves recorded on pre-cleaned metal becomes minor. 

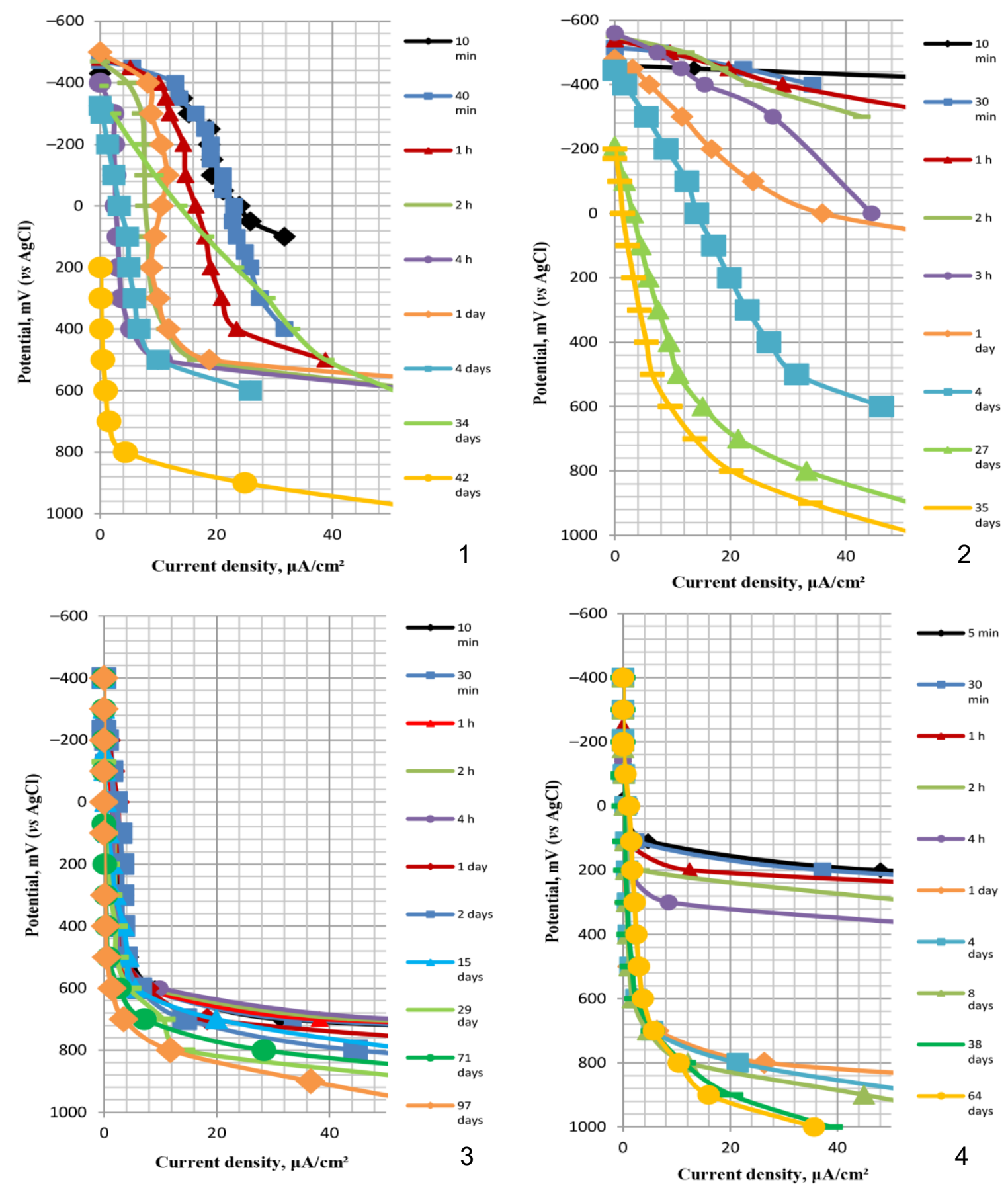

Figure 3. Anodic polarization curves of steel covered with corrosion products in concrete after various hardening times: 1 , concrete without additives; 2 , concrete with addition of $\mathrm{NaCl}$; 3 , concrete with addition of IFKhAN-80; 4, concrete with addition of $\mathrm{NaCl}$ and IFKhAN-80.

Addition of chlorides to concrete, like in the tests with pre-cleaned steel, results in a strong negative shift in the passive film breakdown potentials at small exposure times in comparison with concrete without additives (Figure 5). The $0.4 \mathrm{~V}$ potential corresponds to the growth of pits and is characterized by very high current densities. However, in this case, steel is also passivated after about 40 days of concrete hardening. 

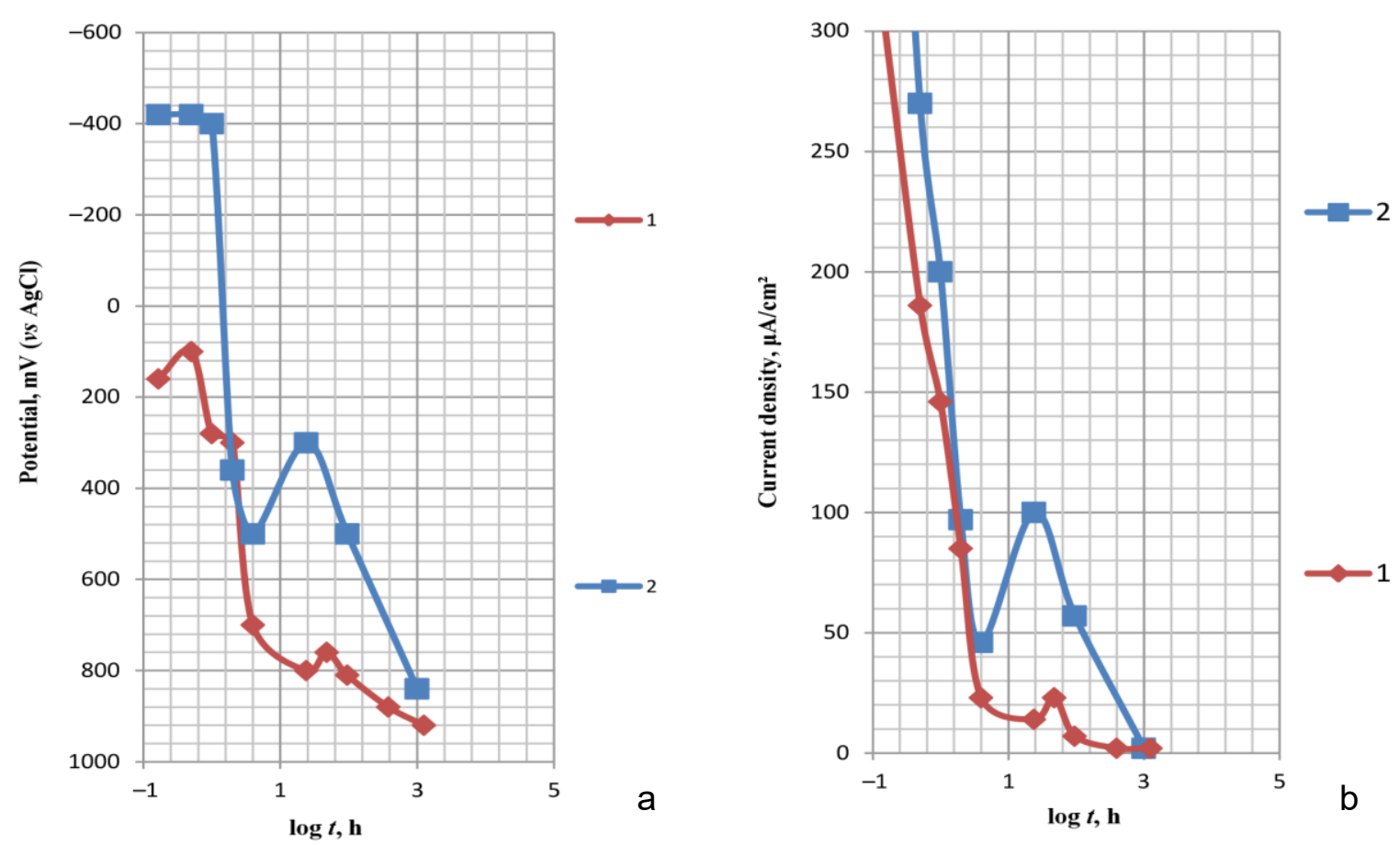

Figure 4. Dependences of breakdown potential and current density in the passive region for pre-cleaned steel $(a)$ and steel covered with corrosion products $(b)$ versus hardening time of concrete containing no additives.
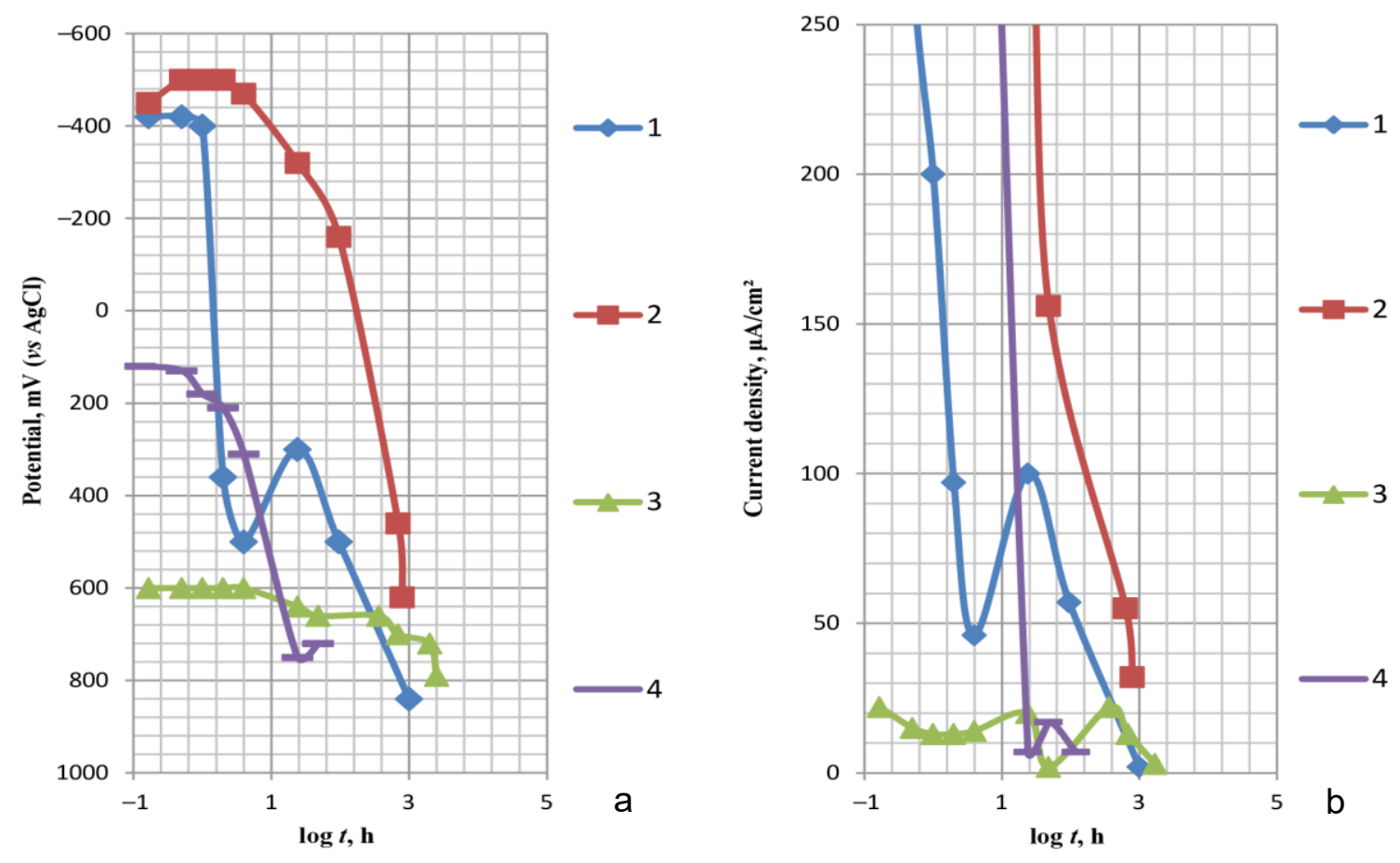

Figure 5. Dependences of breakdown potential (a) and current density in the passive region (b) for steel covered with corrosion products versus time of concrete hardening: 1 , concrete without additives; 2, concrete with addition of $\mathrm{NaCl} ; 3$, concrete with addition of IFKhAN-80; 4 , concrete with addition of $\mathrm{NaCl}$ and IFKhAN-80. 
The time dependences of the breakdown potential and current densities in the passive state obtained in the presence of the inhibitor alone differ fundamentally from those described above. Steel is passivated even in the first minutes of concrete hardening. The breakdown potentials are within $0.7-0.9 \mathrm{~V}$. The current densities in the passive region are very low.

The time dependencies of the breakdown potential and current density in the active region obtained upon simultaneous addition of chlorides and IFKhAN-80 to concrete lie between the corresponding curves for additive-free concrete and for chloride-containing concrete.

Thus, steel covered with corrosion products is more liable to local corrosion in the initial period of concrete hardening than pre-cleaned steel. Like for pre-cleaned steel, chlorides intensify the anodic dissolution of the metal, whereas IFKhAN-80 hinders it. Irrespective of the presence or absence of chlorides, reinforcing steel in concrete undergoes passivation some time after concrete tempering.

\section{Conclusions}

1. Steel is liable to pitting in the initial period of concrete hardening. Pitting is intensified by the presence of chloride in tempering water and/or corrosion products on the metal surface.

2. IFKhAN-80 added with tempering water hinders pit formation on steel during concrete hardening, up to complete suppression of this process.

3. Even at high chloride concentrations in tempering water and in the presence of corrosion products on the metal surface, reinforcing steel in concrete undergoes passivation some time after concrete tempering.

\section{References}

1. S.N. Alekseev, Korroziya i zashchita armatury $v$ betone (Reinforcing steel corrosion and protection in concrete), Moscow, 1968, Izdatel'stvo literatury po stroitel'stvu (Construction literature publishing), $231 \mathrm{pp}$. (in Russian).

2. S.N. Alekseev, V.B. Ratinov, N.K. Rozental' and N.M. Kashurnikov, Ingibitory korrozii stali $v$ zhelezobetonnykh konstruktsiyakh (Steel corrosion inhibitors in reinforced steel structures), Moscow, 1985, Stroiizdat, 272 pp. (in Russian).

3. N.N. Andreev, I.A. Gedvillo, A.S. Zhmakina and D.S. Bulgakov, Korroz.: mater., zashch., 2016, no. 3, 21 (in Russian).

4. N.N. Andreev, I.A. Gedvillo, A.S. Zhmakina, D.S. Bulgakov and S.S. Vesely, Int. J. Corros. Scale Inhib., 2016, 5, no. 4, 319. doi: 10.17675/2305-6894-2016-5-4-2

5. E.V. Starovoitova, N.N. Andreev, I.A. Gedvillo, A.S. Zhmakina, V.F. Stepanova, L.P. Kharitonova and T.L. Zimina, Korroz.: mater., zashch., 2010, no. 8, 31 (in Russian).

6. N.N. Andreev, D.S. Bulgakov, I.A. Gedvillo, A.S. Zhmakina and S.S. Vesely, Int. J. Corros. Scale Inhib., 2014, 3, no. 4, 238. doi: 10.17675/2305-6894-2014-3-4-238-245 
7. N.N. Andreev, D.S. Bulgakov, I.A. Gedvillo, A.S. Zhmakina, Korroz.: mater., zashch., 2014, no. 12, 24 (in Russian).

8. N.N. Andreev, I.A. Gedvillo, A.S. Zhmakina, T.L. Zimina, V.F. Stepanova and L.P. Kharitonova, Praktika protivokorrozionnoi zashchity (Practice of corrosion protection), 2014, no. 1, 14 (in Russian). 